\title{
Screening of Atmospheric Short- and Medium-Chain Chlorinated Paraffins in India and Pakistan using Polyurethane Foam Based Passive Air Sampler
}

Chakra Chaemfa, ${ }^{*}{ }^{\dagger}$ Yue Xu, ${ }^{\dagger}$ Jun Li, ${ }^{\dagger}$ Paromita Chakraborty, ${ }^{\ddagger}$ Jabir Hussain Syed, ${ }^{\dagger}$ Riffat Naseem Malik, Yan Wang, ${ }^{\dagger, \perp}$ Chongguo Tian, ${ }^{\#}$ Gan Zhang, ${ }^{\dagger}$ and Kevin C. Jones ${ }^{\dagger, \nabla}$

${ }^{\dagger}$ State Key Laboratory of Organic Geochemistry, Guangzhou Institute of Geochemistry, Chinese Academy of Sciences, Guangzhou, 510640, China

${ }^{\ddagger}$ SRM Research Institute, SRM University, Kattankulathur, India

${ }^{\S}$ Environmental Biology and Ecotoxicology Laboratory, Department of Environmental Sciences, Quaid-I-Azam University, Islamabad 45320, Pakistan

${ }^{\perp}$ Key Laboratory of Industrial Ecology and Environmental Engineering (MOE), School of Environmental Science and Technology, Dalian University of Technology, Dalian 116024, China

\# Key Laboratory of Coastal Zone Environmental Processes and Ecological Remediation, Yantai Institute of Coastal Zone Research (YIC), Chinese Academy of Sciences(CAS); Shandong Provincial Key Laboratory of Coastal Zone Environmental Processes, YICCAS, Yantai Shandong 264003, P. R. China

${ }^{\nabla}$ Lancaster Environment Centre, Lancaster University, Lancaster, LA1 4YQ, United Kingdom

\section{Supporting Information}

ABSTRACT: Production and use of chlorinated paraffins (CPs) have been increasing in India. Distribution of CPs in the area and vicinity have become a great concern due to their persistency and toxicity. Polyurethane foam based passive air samplers (PUF-PAS) was deployed in order to screen the presence of short- and medium- chain chlorinated paraffins (SCCPs and MCCPs) in the outdoor atmosphere at many sites in India (in winter 2006) and Pakistan (in winter 2011). Concentrations of SCCPs and MCCPs ranged from not detected (ND) to 47.4 and 0 to $38.2 \mathrm{ng} \mathrm{m}^{-3}$ with means of 8.11 and $4.83 \mathrm{ng} \mathrm{m}^{-3}$, respectively. Indian concentrations showed higher average levels of both SCCPs and MCCPs India $\left(10.2 \mathrm{ng} \mathrm{m}^{-3}\right.$ and $3.62 \mathrm{ng} \mathrm{m}^{-3}$ than the samples from Pakistan $\left(5.13 \mathrm{ng} \mathrm{m}^{-3}\right.$ and $\left.4.21 \mathrm{ng} \mathrm{m}^{-3}\right)$. Relative abundance patterns of carbon number are $\mathrm{C} 10>\mathrm{C} 11>\mathrm{C} 12 \sim \mathrm{C} 13$ for SCCPs and $\mathrm{C} 14>\mathrm{C} 15>\mathrm{C} 16 \mathrm{C} 17$ for MCCP with similarity to the profiles of samples from China, the biggest CPs producer in the world. Principal Component Analysis suggested that detected SCCPs and MCCPs in this study originated from the same emission source.

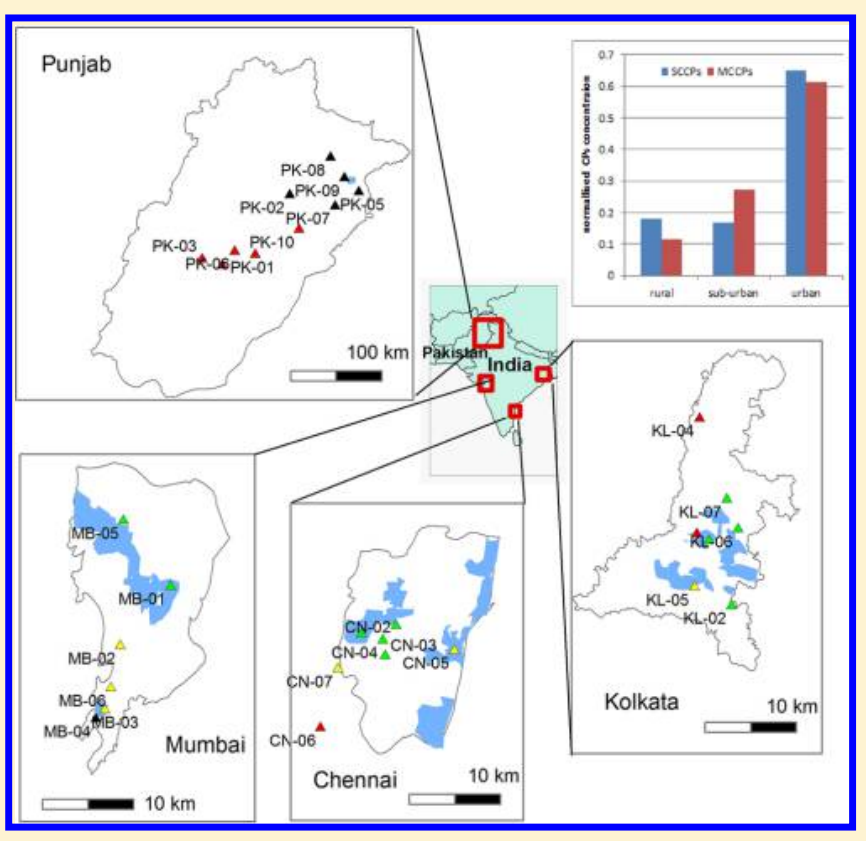

physical and chemical properties to persistent organic pollutants (POPs), such as PCBs, toxaphene and DDT, ${ }^{5,6}$ they are very toxic to human/wildlife and persistent in the environment. ${ }^{7,8} \mathrm{CPs}$ consists of three different groups divided by the number of carbon atoms in the structures; short,

Received: November 21, 2013

Revised: February 28, 2014

Accepted: March 26, 2014

Published: March 26, 2014 


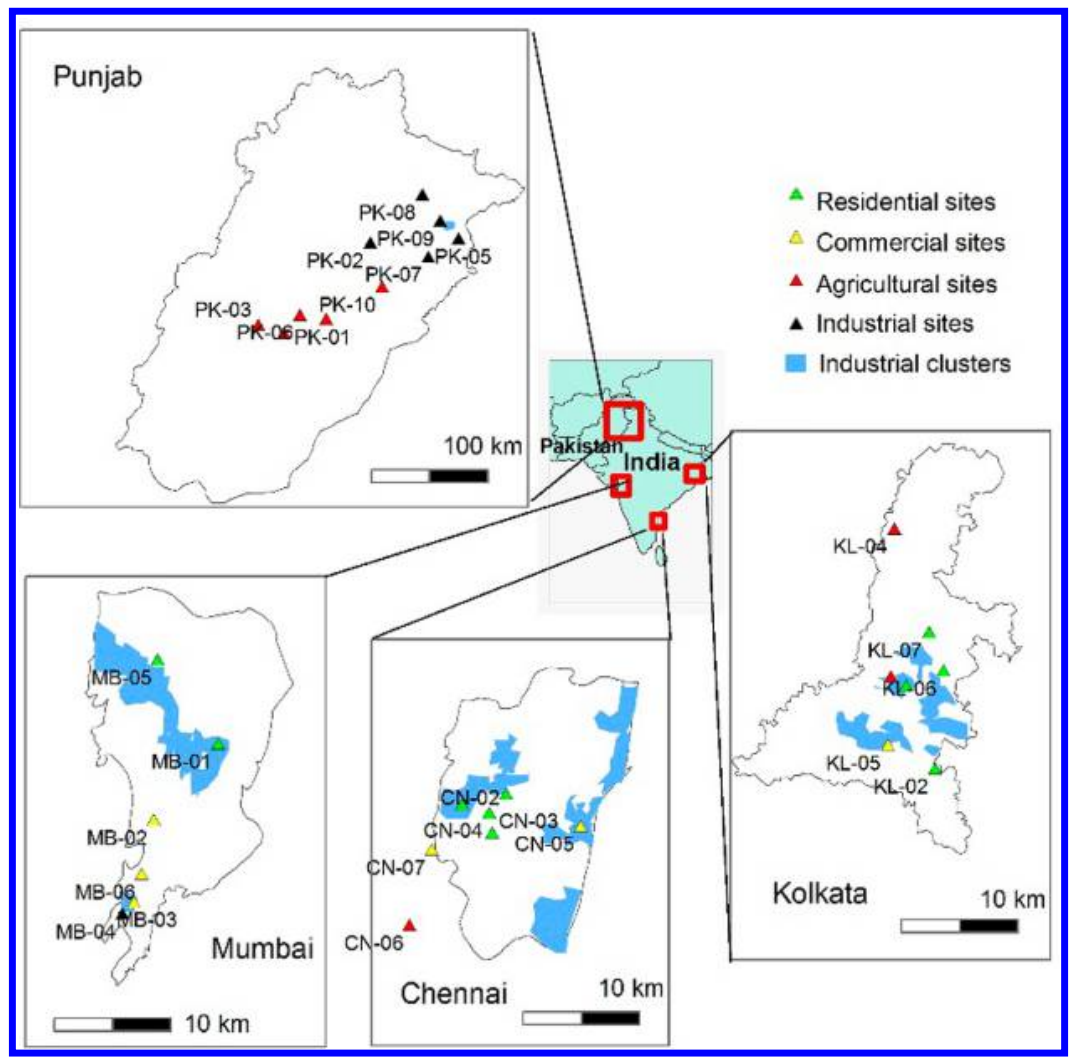

Figure 1. Illustration of sampling sites and detected concentration of SCCPs and MCCPs at each site.

medium, and long chain chlorinated paraffins. The number of carbon for SCCPs, MCCPs, and LCCPs are 10-13, 14-17, and $18-30$, respectively. The short chain chlorinated paraffins (SCCPs), are proposed for listing under the Stockholm Convention due to their persistency and bioaccumulation ${ }^{9}$ whereas the other two CPs; MCCPs and LCCPs, although, they have not yet been proposed under the Convention, have similar properties, however, lower toxicity. IARC or the International Agency for Research on Cancer catagorised SCCPS as group $2 \mathrm{~B}$ which is defined as possibly carcinogenic to humans. ${ }^{10}$ In addition, there is evidence that SCCPs also can cause cancer in rat and mice and harm to aquatic organisms. ${ }^{11}$

Many CPs have a high potential for persistence in the environment and bioaccumulation in the organisms, ${ }^{12-15}$ also are in widespread use. ${ }^{16}$ As expected, they were detected in environmental samples from different compartments and areas $^{4,8,17-21}$ and living samples. ${ }^{22,23}$ Long range transport seems to be a mechanism, ${ }^{24-26}$ like other POPs, transferring $\mathrm{CPs}$ from the point of production and use areas to the other areas, even to the very remote regions and areas with very few human activities. In order to quantify the level of CPs over a large area simultaneously, the use of active air samplers (AAS) could be problematic, with restrictions of cost, intensive maintenance and operation, electricity requirement, and etc. To avoid these issues, AAS are substituted by passive air samplers (PAS) which have been used widely for the monitoring of POPs levels in regional, ${ }^{27}$ national, ${ }^{28}$ and also continental scales ${ }^{29} \cdot{ }^{30}$ As a regional atmospheric observation, it is an important means to confirm local emission sources of POPs, to elucidate atmospheric transport processes and to understand spatial and temporal trends.

In recent years, the South Asia is one of the most prosperous areas of the world, although, rapid economic development and industrialization in this region have resulted in a series environmental problems. Many previous studies conducted in this region have focused on POPs, suggesting that South Asia has become one of the regions of great concern with respect to global POPs pollution. ${ }^{31-33}$ With the influence of high temperatures and the outbreak of monsoons, these POPs can transport to the remote areas. ${ }^{34}$ Despite the large production and usage of CPs in the South Asia region, the study of CP in this area is still limited. There is an urgent need for more studies on the environmental levels of CPs in this continent, particularly the countries with large production and usage, especially China and India. China is the largest producer and consumer of SCCPs in the world. Unsurprisingly, the world's highest atmospheric concentrations of SCCPs were observed ${ }^{8}$ in Chinese cities. In India, chlorinated paraffins are specifically recommended for poly vinyl chloride (PVC) applications in polymer industries. Certain grade can be used as sole plasticizers in relatively hard products, such as flooring compounds, but they are more normally used as partial replacements for phthalate or phosphate primary plasticizers. ${ }^{35}$ The Indian PVC resin industry's capacity currently stands at around 1.3 million tonnes per annum (MTPA). As against this, domestic demand has been growing steadily and has reached almost 2 MTPA. The gap of 0.7 MTPA is filled by imports. ${ }^{35}$ However, the information of how much CPs are used in the PVC production are not available, therefore the amount of usage is unknown. Similarly, information on production and usage of CPs in Pakistan are very limited and there is not yet any official or reliable information available.

With lower sampling cost and the ability for simultaneously sampling in many sites, passive air sampling devices have been deployed for screening the presence of semivolatile organic compounds, especially POPs, in recent years. ${ }^{36,37}$ One of the 
simplest passive air samplers and widely used in many studies for POPs is the polyurethane foam disk. ${ }^{38,28,35,39,40}$ There are some studies that have used polyurethane foam based passive air sampler (PUF-PAS) to determine the CPs in the UK, ${ }^{41}$ China, ${ }^{8,21}$ Japan, $^{8}$ and South Korea. ${ }^{8}$

Since studies or information on the levels of atmospheric CPs are still limited, especially in the South Asia, this study was initiated. PUF-PASs were deployed in India, where CPs are significantly produced, and in Pakistan in winter of 2006 and 2011, respectively, in order to screen, delineate the spatial distribution, and identify congener group profiles of CPs in the atmosphere. The results obtained from this study aim to reduce the information gap on the current level of CPs in the Middle Asian Continent and this would be also a benefit for future studies to use the reported results as a reference or for comparison of centration change in this region.

\section{MATERIALS AND METHODS}

Passive Air Sampling. The air samples were taken from urban, suburban and rural sites by polyurethane foam based passive air samplers (PUF-PAS) $(14.0 \mathrm{~cm}$ diameter; $1.30 \mathrm{~cm}$ thick; $0.0170 \mathrm{~g} \mathrm{~cm}^{-3}$ density). An Indian sampling campaign was conducted at three different areas (Kolkata or KL, Mumbai or $\mathrm{MB}$ and Chennai or $\mathrm{CN}$ with total sample of 20) during the winter season in 2006, whereas in Pakistan or PK (10 samples), the samplers were deployed during the wintertime of 2011 (Figure 1). Details of the sampling campaign in India were described elsewhere. ${ }^{31}$ The Pakistan sampling campaign was conducted near an industrial zone and adjacent rural areas. ${ }^{42} \mathrm{~A}$ summary of the sampling sites and time of deployment can be found in the Supporting Information (SI). The PUF disks were Soxhlet-extracted for $48 \mathrm{~h}$ with methanol and then acetone for $24 \mathrm{~h}$, and dichloromethane (DCM) for $24 \mathrm{~h}$, wrapped with clean aluminum foil baked at $450{ }^{\circ} \mathrm{C}$ for $4-5 \mathrm{~h}$ before use, sealed in Teflon bags and transported to the sampling sites before sampling. The samplers were hang at $1.5-2 \mathrm{~m}$ above ground the open area and air could move freely, around 1.5-2 $\mathrm{m}$ above ground in open area such that air could move freely around them. The samplers were deployed for at least 56 days and 28 days in Pakistan and India, respectively. After each sampler was harvested the PUF disks were wrapped, sealed and transported to the laboratory, and kept at $-18{ }^{\circ} \mathrm{C}$ before analysis.

Sample Extraction and Analysis. The PUF disk air samples were spiked with ${ }^{13} \mathrm{C}$-trans-chlordane as surrogate, and Soxhlet- extracted with dichloromethane (DCM) for $24 \mathrm{~h}$. Activated copper was added to remove elemental sulfur before extraction. Each extract was concentrated and solventexchanged to hexane, then, the extracts were cleaned up by a multilayer column containing anhydrous $\mathrm{Na}_{2} \mathrm{SO}_{4}$, neutral silica gel (3\% deactivated) and neutral alumina (3\% deactivated) from top to bottom, and then by a column containing 50\% (w/ w) sulfuric acid-silica gel, florisil (2\% deactivated) and neutral alumina. The eluent solvent was concentrated to approximately $25 \mu \mathrm{L}$, and ${ }^{13} \mathrm{C}_{8}$-mirex was added to the extracts as the internal standard prior to an instrumental analysis.

Instrumental Analysis and Chemical Standards. SCCPs $\left(\mathrm{C}_{10-13}\right.$ with $\left.\mathrm{Cl}_{5-10}\right)$ and MCCPs $\left(\mathrm{C}_{14-17}\right.$ with $\left.\mathrm{Cl}_{6-10}\right)$ were simultaneously analyzed by gas chromatography electron capture negative ionization low resolution mass spectrometry (GC-ECNI-LRMS) on a DB-5MS column (30 $\mathrm{m} \times 0.25 \mathrm{~mm}$ i.d. $\times 0.25 \mu \mathrm{m}$ film thickness) with methane as the reagent gas. The initial oven temperature was set at $120^{\circ} \mathrm{C}$ for $1 \mathrm{~min}$, and then $15{ }^{\circ} \mathrm{C} / \mathrm{min}$ to $290{ }^{\circ} \mathrm{C}$ held for $15 \mathrm{~min}$. Helium was used as carrier gas at a constant flow of $1.0 \mathrm{~mL} /$ min. Sample volumes of $2 \mu \mathrm{L}$ were injected in the splitless mode at an injector temperature of $280{ }^{\circ} \mathrm{C}$. Temperatures of MSD source and quadrupole were 200 and $150{ }^{\circ} \mathrm{C}$, respectively. The most and second most abundant isotopes of the $[\mathrm{M}-\mathrm{Cl}]^{-}$ions of SCCPs and MCCPs were recorded in the selected ion monitoring (SIM) mode (dwell time of $30 \mathrm{~ms}$ per ion). Three SCCPs $(51.5 \%, 55.5 \%$, and $63 \%$ of $\mathrm{Cl})$, three MCCPs references (42\%, 52\%, and $57 \%$ of $\mathrm{Cl}$ ) from Dr. Ehrenstorfer co., and their mixtures (SI Table S4) were used to establish a linear correlation between chlorine content and total response factor (SI Figure S1). The analytical method was based on previous studies ${ }^{43,44}$ with slight modifications by identify the two most abundant isotope of SCCPs and MCCPs (see SI Table S2) to improve the identification of possible interferences caused by the $\mathrm{CP}$ congeners themselves. The identification of CP congener groups was performed by comparison of retention time, signal shape, and correct isotope ratio according to Reth and Oehme, $(2004)^{44}$ and the quantification method followed the work of Reth et al. $(2005)^{38}$ and Iozza et al., (2008). ${ }^{25}$

Quality Assurance/Quality Contral (QA/QC). In total, seven field and five analytical blanks consisted of pre-extracted PUF disks that were extracted and analyzed in the same manner as the samples. The field blanks were transported to the sampling sites and opened for a few minutes. Then, the blanks were wrapped with the preclean aluminum foil and bought back to the laboratory and stored at $-18{ }^{\circ} \mathrm{C}$ before analysis. All field and analytical blanks spiked with $5 \mu \mathrm{g}$ of SCCP standards with a degree of chlorination of $56.7 \%, 5 \mu \mathrm{g}$ of MCCP standards with a degree of chlorination of $50.3 \%$; and $10 \mathrm{ng}{ }^{13} \mathrm{C}_{10}$-transchlordane were simultaneously analyzed. The concentration of SCCP, MCCP and ${ }^{13} \mathrm{C}_{10}$-trans-chlordane standards were in the range of $82-96 \%, 74-80 \%$, and $81-90 \%$, respectively. There are no significant differences between lab and field blanks, or between the blanks taken from Pakistan and India. The method detection limit (MDL) was defined as the mean of the blanks plus 3 times the standard deviation and the MDL values for SCCPs and MCCPs were 2.65 and $1.80 \mathrm{ng} / \mathrm{m}^{3}$, respectively. Any samples with values lower than MDL are treated not detected (ND). The surrogate recoveries for ${ }^{13} \mathrm{C}$-transchlordane in all samples ranged from 70.6 - 97.2\%, with an average of $77.5 \%$. The reported results were all corrected by mean concentration of the blanks (field and analytical blanks) but not by the surrogate recoveries.

Air Sampling rate of SCCPs and MCCPs. Li et al. (2006) conducted a study to deploy the PUF-PAS in the East Asian countries; China, South Korea, and Japan in order to investigate level of CPs in these countries. A sample rate $(R)$ for CPs was determined by deploying AAS and PAS simultaneously for 90 days in Guangzhou Institute of Geochemistry, Guangzhou, China. The sampling rate reported by Li et al. $\left(4.2 \mathrm{~m}^{3} \mathrm{~d}^{-1}\right)$ was applied to calculate the atmospheric concentrations of SCCPs and MCCPs in this study. The results of MCCPs which trend to bound with particular in atmosphere, could be slightly overestimate since the calibration study for MCCPs were not conducted. However, a recent calibration study of polycyclic aromatic compounds (PACs) ${ }^{45}$ in which low molecular weight PACs are in the gas phase and medium and high PCAs tend to be in the particulate phase found that the sampling rates for the different congeners were in the same magnitude $\left(5.1 \pm 3.7 \mathrm{~m}^{3}\right)$ 


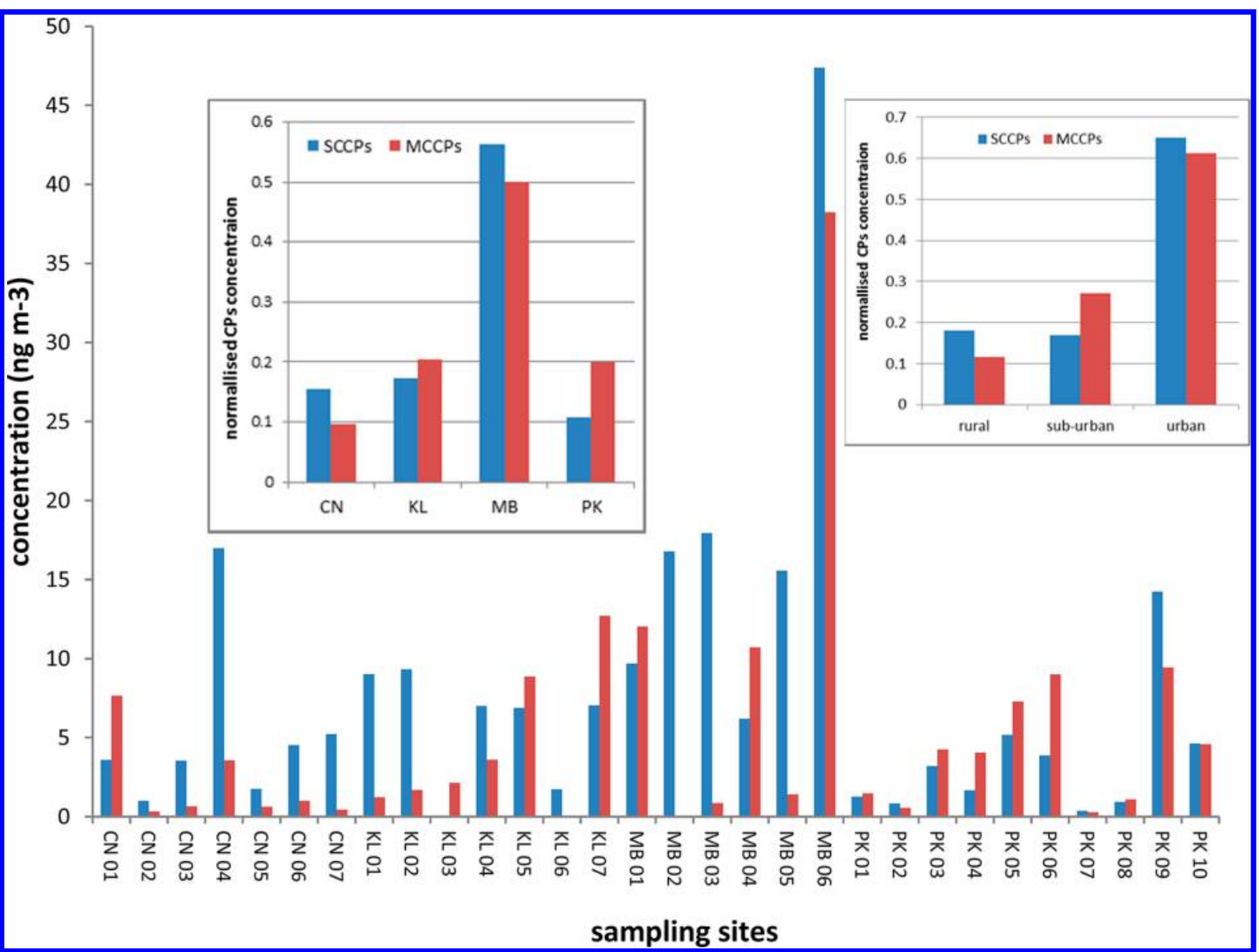

Figure 2. Total concentration of detected congeners for SCCPs and MCCPs at each site and the profiles of normalized concentration of SCCPs and MCCPs categorized by level of urbanisation and cities. Normalized concentration is derived from concentration of SCCPs (or MCCPs) detected divided by total concentration of SCCPs (or MCCPs) for each category.

day). Therefore, it is worth to mention that the reported results of MCCPs in this study could be slightly overestimated.

Statistical Analysis. Principal component analysis (PCA) was conducted in this study to support an interpretation of the results on the congener and homologue profiles of SCCPs and MCCPs. PCA was accomplished using SPSS 16.0 for window. The concentration of SCCPs and MCCPs were normalized by factor extraction with an eigenvalue $>1$ after Varimax rotation. Kaiser-Meyer-Olkin and Bartlett's sphericitity tests were performed to examine the validity of PCA before conducting PCA analysis.

\section{RESULTS AND DISCUSSION}

Atmospheric Concentrations of CPs. Concentrations of SCCPs and MCCPs in this study ranged from ND (KL 03) to 47.4 and ND (KL 06 and MB 02) to $38.2 \mathrm{ng} \mathrm{m}^{-3}$ with means of 8.11 and $4.83 \mathrm{ng} \mathrm{m}^{-3}$, respectively. Comparison of the concentrations detected between Indian and Pakistan showed higher than average levels of both SCCPs and MCCPs in India $\left(10.2 \mathrm{ng} \mathrm{m}^{-3}\right.$ and $\left.3.62 \mathrm{ng} \mathrm{m}^{-3}\right)$ than Pakistan $\left(5.13 \mathrm{ng} \mathrm{m}^{-3}\right.$ and $\left.4.21 \mathrm{ng} \mathrm{m}^{-3}\right)$. As expected, the highest concentrations of SCCPs and MCCPs were found at the same site (MB 06) in Colaba, Mumbai, India and the concentration were 47.4 and $38.2 \mathrm{ng} \mathrm{m} \mathrm{m}^{-3}$. The site is located in a densely populated industrialized area. Similarly, among the 10 sampling sites in Pakistan, the highest SCCPs $\left(14.23 \mathrm{ng} \mathrm{m}^{-3}\right)$ and MCCPs (9.45

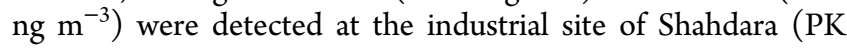

09). Nonetheless, the concentration pattern of CPs in Pakistan is not very clear, the level of both SCCPs and MCCPs were found to be very low in some industrial sites, urban area (PK 02, 07, and 08) and moderately high at the agricultural site, rural area (PK 06). Due to lacking of official or reliable production and use data for CPs in Pakistan, a possible explanation of this event is that there could be some local CPs sources where some plastic, rubber, and paint plants are randomly located in Pakistan. Figure 2 presents the concentration of SCCPs and MCCPs at each site and the concentration profiles separated by degree of urbanisation. It is noted that the sampling campaign the sites in India and Pakistan were conducted in different years, 2006 and 2011, respectively. The sampling sites were divided into three groups; urban, suburban, and rural, and total concentration (from both countries) of SCCPs and MCCPs for each group was normalized for comparison. It is clear that the level of CPs in the urban area shows the highest level of both SCCPs and MCCPs, following suburban and rural areas.

The detected levels of CPs in India from this study are fairly low when compared with the atmospheric samples from China, ${ }^{8,46}$ which is the world biggest CPs producer, ${ }^{13}$ approximately 10 times lower. However, CPs in Indian air are significant higher than ambient air in Japan, ${ }^{8}$ South Korea, ${ }^{8}$ and Pakistan (in this study), where the concentration of CPs in these three countries are comparable (see Table 1). In the European zone, few atmospheric CPs concentrations in the 
Table 1. Summary of Detected CPs $\left(\mathrm{ng} \mathrm{m}^{-3}\right)$ in This Study with Previous Studies

\begin{tabular}{|c|c|c|}
\hline $\begin{array}{l}\text { sampling country } \\
\text { (sampling year) }\end{array}$ & sample & \\
\hline \multicolumn{3}{|l|}{$\begin{array}{l}\text { Using Passive Air } \\
\text { Sampler }\end{array}$} \\
\hline $\begin{array}{l}\text { India (2006) (this } \\
\text { study) }\end{array}$ & ambient air & $\begin{array}{l}\text { SCCPs: not detected }-47.4 \\
\text { MCCPs: not detected }-38.2\end{array}$ \\
\hline $\begin{array}{l}\text { Pakistan (2009) } \\
\text { (this study) }\end{array}$ & ambient air & $\begin{array}{l}\text { SCCPs: } 0.37-14.2 \text { MCCPs: } 0.29- \\
\quad 9.45\end{array}$ \\
\hline China $(2008)^{8}$ & ambient air & SCCPs: $13.5-517$ \\
\hline $\begin{array}{l}\text { South Korea } \\
(2008)^{8}\end{array}$ & ambient air & SCCPs: $0.60-8.96$ \\
\hline $\mathrm{UK}(2003)^{41}$ & ambient air & $\begin{array}{l}\operatorname{SCCPs}^{a}: 0.62-25.8 \operatorname{MCCPs}^{a}: \\
\quad 1.59-16.4\end{array}$ \\
\hline China $(2010)^{21}$ & ambient air & $\begin{array}{l}\operatorname{SCCPs}^{a}: 0.95-106 \operatorname{MCCPs}^{a}: \\
\quad 0.10-231\end{array}$ \\
\hline \multicolumn{3}{|l|}{$\begin{array}{l}\text { Using Active Air } \\
\text { Sampler }\end{array}$} \\
\hline $\begin{array}{l}\text { China }(2012)^{50} \\
\text { Beijing }\end{array}$ & & SCCPs: $1.9-332$ \\
\hline $\mathrm{UK}(2003)^{41}$ & $\begin{array}{l}\text { ambient air and } \\
\text { indoor air }\end{array}$ & $\begin{array}{l}\text { SCCPs: }<0.185-3.430 \text { MCCPs: } \\
0.810-14.000\end{array}$ \\
\hline UK (1997) 51 & ambient air & SCCP: $0.0054-1.085$ \\
\hline Norway $\left({ }^{b}\right)$ & ambient air & SCCPs: $0.009-0.057$ \\
\hline Sweden $(2006 / 7)^{49}$ & indoor air & SCCPs and MCCP: 5-210 \\
\hline
\end{tabular}

UK, Sweden, and Norway were reported. Unfortunately, official information or reports of atmospheric CPs level in past 10 years from the North and South America are presently unavailable. Summary of CPs in the atmosphere from diffident countries are listed in Table 1. It is worth to mention that the level of CPs detected in passive and active air samplers from the same country, such as China (see Table 1) are in the same magnitude. It suggests that PUF-PAS is an efficient tool to use for monitoring the level of atmospheric CPs when the active air sampling technique is not available.

Even though, lack of information on the production of CPs (and each group; SCCPs, MCCPs, and LCCPs) in India aforementioned, around $10-17 \%$ are estimated to be added for the plastic or PVC production. ${ }^{35}$ Unfortunately, without the information of CPs for other applications in India, such as for working metal fluids, it should be noted that the following CPs production and usage only based on the polymer industry. Based on this consumption and estimated annual PVC production in India (2 million tonnes), Estimation of CPs used as additive for this matter are approximately 200000 to 340000 tonnes a year. The production of CPs in China alone in 2007 were more than 600000 tonnes. ${ }^{13}$ On the contrary, it was suggested that the production and use in Europe ${ }^{13}$ (15000 and 4000 tonnes for SCCPs and MCCPs, respectively) were less than 20000 tonnes. Considering the magnitude of production and use from China, Europe, and India with

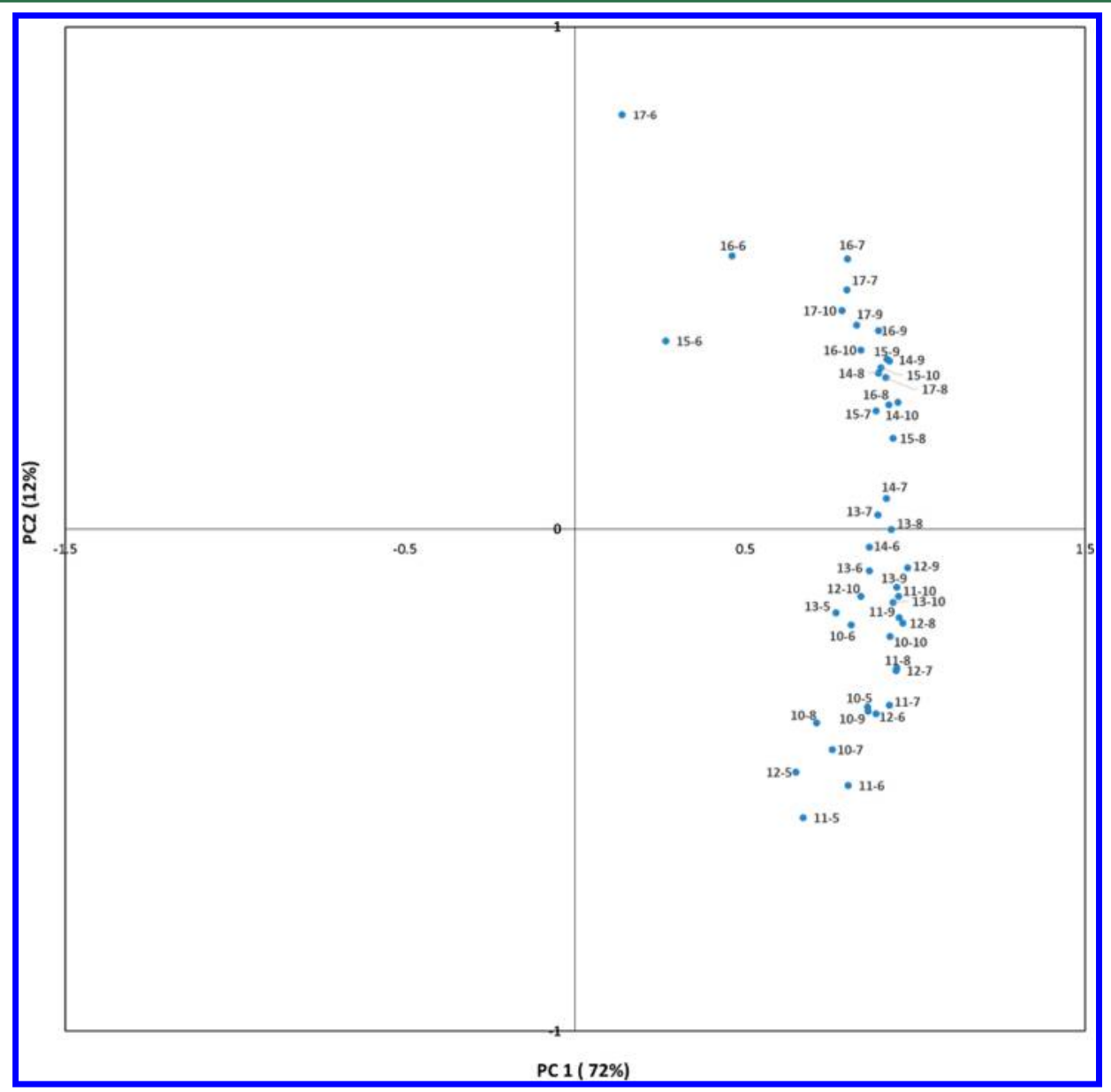

Figure 3. Factor loading plot of SCCPs and MCCP congeners in air samples from India and Pakistan. Front and rear numbers represent the number of carbon and chlorine atoms of the congener, for example, $11-5$ represent $\mathrm{C}_{11} \mathrm{Cl}_{5}$. 


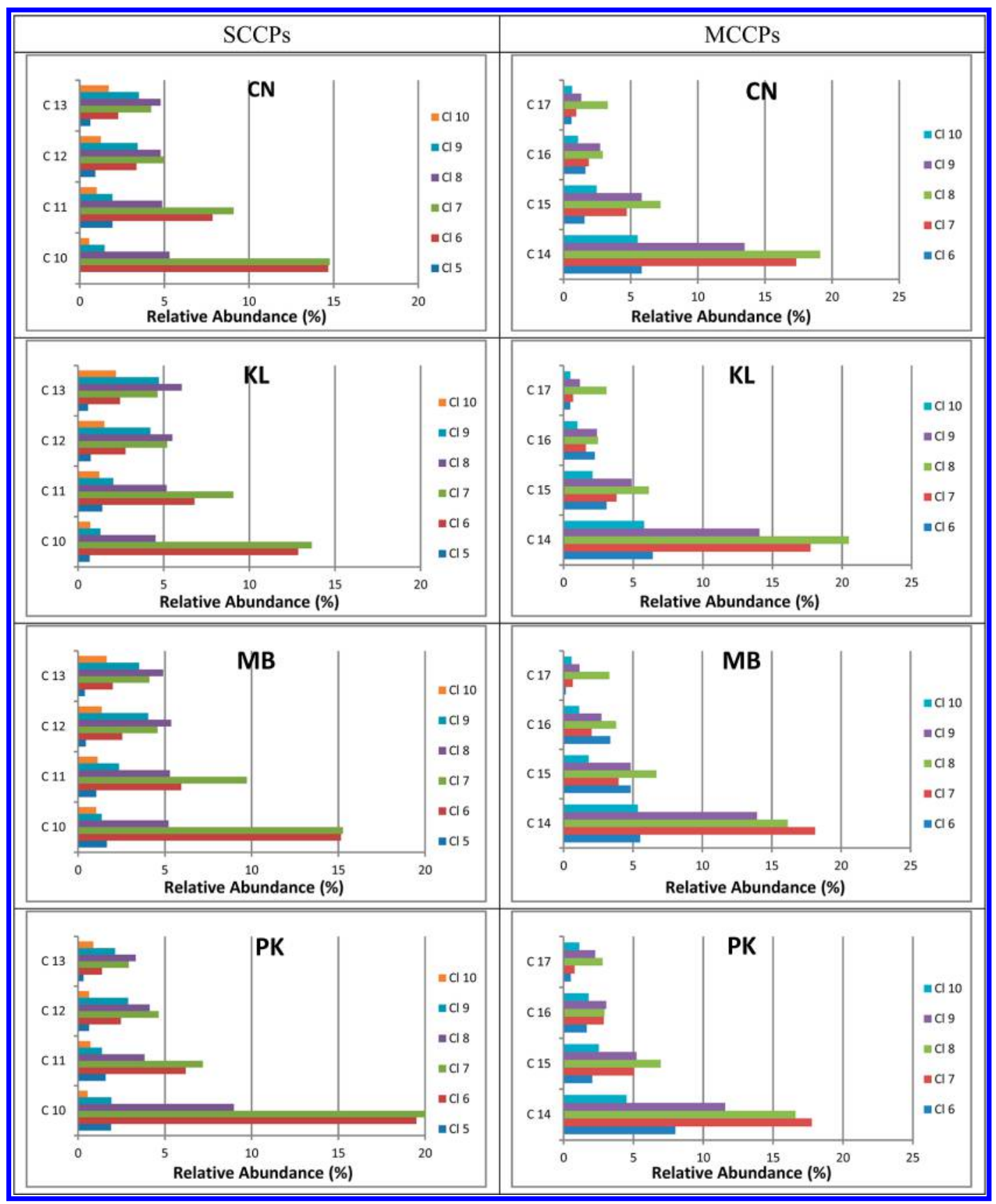

Figure 4. Composition profiles of SCCPs and MCCPs at different cities.

detected CPs in these area, the results well agree and are comparable.

It is worthy of mention that large quantity of plastic products containing CPs has been used in Europe, nevertheless the production of CPs is limited and small. CPs could be released from these products, however the levels of detected atmospheric CPs are still much less than the level in this study. The reason behind this fact is that possible main paths of CPs from plastic products to the environment are disposal and recycle of these plastic. The emission rate depends on the extent of dust control at the facility. ${ }^{13}$ Undoubtedly the restriction, regulation, and technology for controlling the disposal and recycling in India, Pakistan, and China are minimal and ineffective when compares with European countries.
Like other POPs such as PCBs, PBDEs, and PAHs, temperature plays an important role in their fate and distribution in the environment. Lower weight congeners tend to associate with the gaseous phase while the heavier congeners trend to bind with the particular phase. These compounds, including CPs can volatile during periods of high temperatures and deposit when the temperature drops. It is worth to mention that the concentration of CPs in India and Pakistan in this study, especially SCCPs (lower $K_{\mathrm{OA}}$ than MCCPs and trend to bind in gaseous phase) could be higher if the sampling campaign was completed during or cover periods of high ambient temperature such as in the summer. Previous seasoning studies on the CPs suggested that levels of CPs were higher in the autumn than the spring ${ }^{8}$ and higher in the summer than the winter. ${ }^{21}$ 


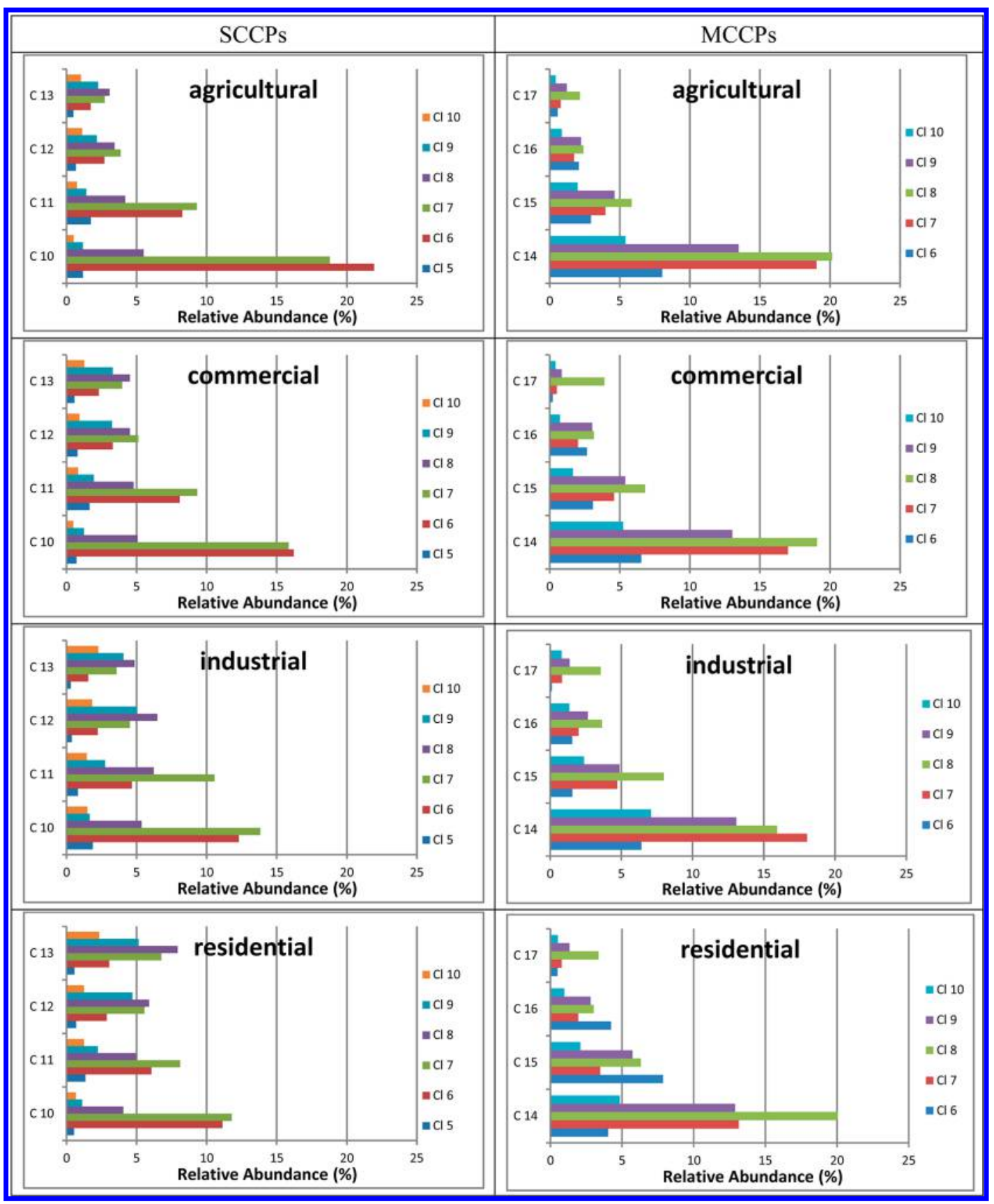

Figure 5. Composition profiles of SCCPs and MCCPs catagorised by main activity of the sampling sites.

Principal Component Analysis (PCA). Principal component analysis has been applied to this study for an investigation of potential sources of SCCPs and MCCPs in the air samples from India and Pakistan. A factor loading plot is presented in Figure 3. The first two principal components; PC 1 and PC 2 accounted for. $83 \%$ with $72 \%$ accounted for PC1 alone. From the plot, the samplers are clearly divided into 2 groups, SCCPs (C10 to C13) and MCCPs (C14 to C17) with some congeners which separate from the MCCP group. Interestingly, these congeners are MCCPs containing 6 atoms of chlorine; $\mathrm{C}_{15} \mathrm{Cl}_{6}$, $\mathrm{C}_{16} \mathrm{Cl}_{6}$, and $\mathrm{C}_{17} \mathrm{Cl}_{6}$. Another interesting observation from the plot found that the congeners located furthest from the most dense of gathering of congeners and from PC2 of the SCCP group are congeners with lower chlorination degree in the structure, for examples, $\mathrm{C}_{11} \mathrm{Cl}_{5}, \mathrm{C}_{11} \mathrm{Cl}_{6}$, and $\mathrm{C}_{12} \mathrm{Cl}_{5}$.
The results from the analysis suggested that those SCCPs and MCCPs should be originated from the same source. With lower chlorinated degree in the structure of SCCPs and MCCPs, it is possible that these congeners travel further from the emission source when compare with the compounds having a higher degree of chlorination. Alternatively, these lower chlorination compounds might be the yield generated from dechlorinated and/or degradation of higher chlorination compound. However, the complex structure and properties of the compounds makes the study of the pathways of degradation for chlorinated paraffins difficult to achieve. 


\section{ATMOSPHERIC CONGENER HOMOLOGUE PROFILES OF SCCPS AND MCCPS}

Figure 4 demonstrates and compares homologue profiles of SCCPs and MCCPs in the air samples deployed in India: Kolkata (KL), Mumbai (MB), Chennai (CN), and in Pakistan: Punjab (PK). Relative abundance patterns of carbon number in the structure from these four cities for SCCPs and MCCPs are $\mathrm{C} 10>\mathrm{C} 11>\mathrm{C} 12>\mathrm{C} 13$ and $\mathrm{C} 14>\mathrm{C} 15>\mathrm{C} 16>\mathrm{C} 17$, respectively. The SCCPs patterns are fairly similar with the results detected in PAS results from China, Japan, and South Korea, ${ }^{8}$ the only difference is that the $\mathrm{C} 11$ is slightly higher than C10. However, considering only the pattern of SCCPs in China, the homologue patterns of this study and the reports by $\mathrm{Li}$ et al. are identical.

Guo et al. (2012) ${ }^{47}$ analyzed three commercial CP mixtures which are CP-42, CP-52, and CP-70, they have been used intensively in China and they are accounted for $80 \%$ of total production of CPs in China. ${ }^{1}$ The results suggest $\mathrm{C} 10$ and $\mathrm{C} 11$ are the largest of the components in C-42 and C-52, whereas $\mathrm{C} 10$ and C-12 are the highest in C-72 (see SI Figure S2). Unfortunately, the commercial CP mixtures in South Asia, India, and Pakistan, are not well documented, therefore, the composition of the mixtures are not available. The pattern of carbon number of SCCPs are similar to pattern of commercial SCCPs in China, however, there is insufficient evidence to suggest that the application and usage of SCCPs used in India and Pakistan are similar. The variation of SCCPs patterns do not only depend on commercial formula, but also physicalchemical properties, and meteorological. For example, vapor pressure is found to be a very important factor for SCCPs. The vapor pressure decreases with an increasing of carbon-chain length and degree of chlorination. ${ }^{48}$ The concentration of SCCPs and the pattern of carbon atom might be different for the samples sampling in the different seasons.

There are few studies into the presence of MCCPs in air, however, Wang and his colleagues recently studied the decomposition of CPs and they reported the atmospheric concentrations and profiles of MCCPs obtained from the samples in Pearl River Delta (PRD), China. ${ }^{46}$ The results in PRD and four sites in this study are alike, with C14 as a dominate homologue. Similarly, C14 homologue was the highest homologue found in the indoor air samples from Stockholm, Sweden. ${ }^{49} \mathrm{C} 14$ homologue is also found to be dominant in other different sample matrixes, such as dust, ${ }^{9,49}$ soil,$^{46}$ sediment, $^{10}$ and living samples. ${ }^{22,25,26}$ The lack of calibration study for the sampling rate of PUF-PAS for MCCPs suggests that the results of this study could be lower than the actual MCCPs in the atmosphere. In addition, MCCPs are heavier than SCCPs and they are mainly in the particular phase, therefore PUF-PAS might not well capture MCCPs presented in the atmosphere.

Considering the homologue patterns for SCCPs and MCCPs with different activities of sampling sites, the sampling sites were divided into four different groups, agricultural, commercial, industrial, and residential. The profiles of SCCPs and MCCPs for these activities are presented in Figure 5. It is very obvious, with the exception of SCCPs in residential activity, that the distribution of SCCPs and MCCPs, from high to low, is varied in the opposite direction with their number of carbon in the compounds $(\mathrm{C} 10>\mathrm{C} 11>\mathrm{C} 12 \sim \mathrm{C} 13$ and $\mathrm{C} 14>\mathrm{C} 15>$ $\mathrm{C} 16>\mathrm{C} 17)$. This pattern is similar to the pattern found in commercial mixture CPs produced in China, while the C11 is the major composition in $\mathrm{CP}$ mixture produced from North America, Germany, and UK. ${ }^{22,29}$ The results from PCA reveal that SCCPs and MCCPs are likely to be from the same source, however, to confirm whether SCCPs and MCCPs used and produced are identical with China, more investigation and information is required.

In India, SCCPs levels found are generally higher than MCCPs but it was opposite story in Pakistan (see Figure 2). This might reflect the different application of CPs in these two countries. As textiles are a major industry in Pakistan and long chain CPs (MCCPs and LCCPs) are used as flame retardant for rubber and textile, this could be attributed to the higher MCCPs level than SCCPs in Pakistan. Even though, CPs used as additive for PCV production is MCCPs and they are used in for this purpose mainly in India at mentioned earlier, the MCCPs in the Indian air samples from the site in Mumbai and Chennai were less than SCCPs. This could infer that the application and usage of SCCPs and MCCPs in the area might play an important role in the level of these compounds in the atmosphere and the environment.

\section{SPATIAL DISTRIBUTION}

Long-range transportation might have a minimal influence on the mobilization of CPs according to the previous reports from the study of spatial and distribution of SCCPs conducted in China, Japan, and South Korea. ${ }^{8}$ Calculation by The Fugacity Level III and OECD LRT tool models suggested CPs trend to bind with sediment and soil. Their present in the atmosphere is very small compared to the other environmental compartments and the amount in the air declines with the number of chlorine atoms in the structure. ${ }^{13}$ Hence, a primary source seems to play an important role of CPs distribution in the local atmosphere, rather than long-range transportation. Considering the important properties controlling the chemical transportation, the volatility of MCCPs is higher than SCCPs, this makes MCCPs tend to bind with particles and are more easily deposited to the terrestrial compartment and to sink into the riverine environment. Yan et al. ${ }^{21}$ reported the levels of SCCPs and MCCPs in air, soil, and deposition samples; they suggested that the atmospheric transport of CPs is preferred mechanism for lighter CPs, such as SCCPs, rather than heaver CPs (MCCPs and LCCPs). Results from principal component analysis (PCA) of this study suggest that the congener with lower degree of chlorination might probably not be from the local sources.

Although some studies suggested that the long-range transport does not play an important role in atmospheric distribution of $\mathrm{CPs}^{8}{ }^{8}$ but they potential undergo long-range atmospheric transport. The combination of the close proximity to the biggest CPs producer in the world, China and a growing in industrialization in India and Pakistan, the atmospheric levels of CPs are potential higher and could pose a high risk to humans and wildlife in the future. The concentrations of CPs in this study could be useful for the future study in order to compare the change of CPs in this region. With current information and knowledge of these compounds in the South Asia with respect to their fate and behavior in the environment, occurrence and toxicity, further studies on these aspects are urgently needed in order to get a better understanding of these CPs in the environment. Also, calibration study or information for passive air sampler of different CPs is also required for more accuracy of the results using the passive air sampler. 


\section{ASSOCIATED CONTENT}

\section{S Supporting Information}

Additional information as noted in the text. This material is available free of charge via the Internet at http://pubs.acs.org.

\section{AUTHOR INFORMATION}

\section{Corresponding Author}

*Phone: 86208529 1508; fax: 86208529 0706; e-mail: chaemfa@gmail.com.

\section{Notes}

The authors declare no competing financial interest.

\section{ACKNOWLEDGMENTS}

Funding was supported by the Chinese Academy of Sciences (No. KZCX2-YW-GJ02), Ministry of Environmental Protection (No. 201209018) and the Natural Science Foundation of China (NSFC) (No. 41125014 and 40821003).

\section{REFERENCES}

(1) Gawor, A.; Wania, F. Using quantitative structural property relationships, chemical fate models, and the chemical partitioning space to investigate the potential for long range transport and bioaccumulation of complex halogenated chemical mixtures. Environ. Sci.: Processes Impacts 2013, 15 (9), 1671-1684.

(2) What are chlorinated paraffins? http://www.eurochlor.org/ chlorinated-paraffins-(cpsg)/what-are-chlorinated-paraffins.aspx (accessed November 14, 2013).

(3) Bayen, S.; Obbard, J. P.; Thomas, G. O. Chlorinated paraffins: A review of analysis and environmental occurrence. Environ. Int. 2006, 32 (7), 915-929.

(4) Barber, J. L.; Sweetman, A. J.; Thomas, G. O.; Braekevelt, E.; Stern, G. A.; Jones, K. C. Spatial and temporal variability in air concentrations of short-chain $\left(\mathrm{C}_{10}-\mathrm{C}_{13}\right)$ and medium-chain $\left(\mathrm{C}_{14}-\mathrm{C}_{17}\right)$ chlorinated $\mathrm{n}$-alkanes measured in the $\mathrm{UK}$ atmosphere. Environ. Sci. Technol. 2005, 39 (12), 4407-4415.

(5) Santos, F. J.; Parera, J.; Galceran, M. T. Analysis of polychlorinated n-alkanes in environmental samples. Anal. Bioanal. Chem. 2006, 386 (4), 837-857.

(6) Feo, M. L.; Eljarrat, E.; Barcelo, D. Occurrence, fate and analysis of polychlorinated $\mathrm{n}$-alkanes in the environment. Trends Anal. Chem. 2009, 28 (6, Sp. Iss. SI), 778-791.

(7) Poremski, H. J.; Wiandt, S.; Knacker, T. Chlorinated paraffins-A further POP to consider? Organohalogen Compd. 2001, 52, 397-400.

(8) Li, Q.; Li, J.; Wang, Y.; Xu, Y.; Pan, X.; Zhang, G.; Luo, C.; Kobara, Y.; Nam, J.-J.; Jones, K. C. Atmospheric short-chain chlorinated paraffins in China, Japan, and South Korea. Environ. Sci. Technol. 2012, 46 (21), 11948-11954.

(9) EPA. Short-Chain Chlorinated Paraffins (SCCPs) and Other Chlorinated Paraffins Action Plan, 2009.

(10) IARC. Summaries and Evaluations. Chlorinated Paraffins (Group 2B), 1990; p 55

(11) OSPAR. Background Document on Short Chain Chlorinated Paraffins; OSPAR Commission: London, U.K., 2001.

(12) Wang, Y.; Zhu, H.; Li, Q.; Zheng, Q. Overview of chlorinated paraffins in the environment. Sci. Technol. Rev. 2012, 30 (22), 68-72.

(13) Muir, D. Environmental levels and fate. In Chlorinated Paraffins; Boer, J., Ed.; Springer: Berlin Heidelberg, 2010; pp 107-133.

(14) Zeng, L.; Wang, T.; Wang, P.; Liu, Q.; Han, S.; Yuan, B.; Zhu, N.; Wang, Y.; Jiang, G. Distribution and trophic transfer of short-chain chlorinated paraffins in an aquatic ecosystem receiving effluents from a sewage treatment plant. Environ. Sci. Technol. 2011, 45 (13), 55295535 .

(15) Thompson, R.; Vaughan, M. Medium-chain chlorinated paraffins (MCCPs): A review of bioaccumulation potential in the aquatic environment. Integr. Environ. Assess. Manage. 2014, 10 (1), 7886.
(16) Tomy, G. T.; Muir, D. C. G.; Stern, G. A.; Westmore, J. B. Levels of $\mathrm{C}_{10}-\mathrm{C}_{13}$ polychloro-n-alkanes in marine mammals from the Arctic and the St. Lawrence River estuary. Environ. Sci. Technol. 2000, 34 (9), 1615-1619.

(17) Houde, M.; Muir, D. C. G.; Tomy, G. T.; Whittle, D. M.; Teixeira, C.; Moore, S. Bioaccumulation and trophic magnification of short- and medium-chain chlorinated paraffins in food webs from Lake Ontario and Lake Michigan. Environ. Sci. Technol. 2008, 42 (10), 3893-3899.

(18) Zeng, L.; Wang, T.; Han, W.; Yuan, B.; Liu, Q.; Wang, Y.; Jiang, G. Spatial and vertical distribution of short chain chlorinated paraffins in soils from wastewater irrigated farmlands. Environ. Sci. Technol. 2011, 45 (6), 2100-2106.

(19) Castells, P.; Parera, J.; Santos, F. J.; Galceran, M. T. Occurrence of polychlorinated naphthalenes, polychlorinated biphenyls and shortchain chlorinated paraffins in marine sediments from Barcelona (Spain). Chemosphere 2008, 70 (9), 1552-1562.

(20) Chen, M. Y.; Luo, X. J.; Zhang, X. L.; He, M. J.; Chen, S. J.; Mai, B. X. Chlorinated paraffins in sediments from the Pearl River Delta, South China: Spatial and temporal distributions and implication for processes. Environ. Sci. Technol. 2011, 45 (23), 9936-9943.

(21) Wang, Y.; Li, J.; Cheng, Z.; Li, Q.; Pan, X.; Zhang, R.; Liu, D.; Luo, C.; Liu, X.; Katsoyiannis, A.; Zhang, G. Short- and medium-chain chlorinated paraffins in air and soil of subtropical terrestrial environment in the Pearl River Delta, South China: Distribution, composition, atmospheric deposition fluxes, and environmental fate. Environ. Sci. Technol. 2013, 47 (6), 2679-2687.

(22) Kalantzi, O. I.; Alcock, R. A. Short-chain chlorinated paraffins in biota-Levels and effects. Global Nest J. 2012, 14 (1), 66-71.

(23) Jiang, G.; Chen, L.-g.; He, Q.-s.; Meng, X.-z.; Feng, Y.-b.; Huang, Y.-m.; Tang, C.-m. Contamination characteristics of shortchain chlorinated paraffins in edible fish of Shanghai. Huanjing Kexue 2013, 34 (9), 3374-3380.

(24) Chen, M. Y.; Luo, X. J.; Zhang, X. L.; He, M. J.; Chen, S. J.; Mi, B. X. Chlorinated paraffins in sediments from the Pearl River Delta, South China: Spatial and temporal distributions and implication for processes. Environ. Sci. Technol. 2011, 45 (23), 9936-9943.

(25) Gao, Y.; Zhang, H. J.; Su, F.; Tian, Y. Z.; Chen, J. P. Environmental occurrence and distribution of short chain chlorinated paraffins in sediments and soils from the Liaohe River Basin, P. R. China. Environ. Sci. Technol. 2012, 46 (7), 3771-3778.

(26) Zeng, L. X.; Zhao, Z. S.; Li, H. J.; Wang, T.; Liu, Q.; Xiao, K.; Du, Y. G.; Wang, Y. W.; Jiang, G. B. Distribution of short chain chlorinated paraffins in marine sediments of the East China Sea: Influencing factors, transport and implications. Environ. Sci. Technol. 2012, 46 (18), 9898-9906.

(27) Wang, X. P.; Gong, P.; Yao, T. D.; Jones, K. C. Passive air sampling of organochlorine pesticides, polychlorinated biphenyls, and polybrominated diphenyl ethers across the Tibetan Plateau. Environ. Sci. Technol. 2010, 44 (8), 2988-2993.

(28) Zhang, G.; Chakraborty, P.; Li, J.; Sampathkumar, P.; Balasubramanian, T.; Kathiresan, K.; Takahashi, S.; Subramanian, A.; Tanabe, S.; Jones, K. C. Passive atmospheric sampling of organochlorine pesticides, polychlorinated biphenyls, and polybrominated diphenyl ethers in urban, rural, and wetland sites along the coastal length of India. Environ. Sci. Technol. 2008, 42 (22), 8218-8223.

(29) Jaward, F. M.; Farrar, N. J.; Harner, T.; Sweetman, A. J.; Jones, K. C. Passive air sampling of PCBs, PBDEs, and organochlorine pesticides across Europe. Environ. Sci. Technol. 2004, 38 (1), 34-41.

(30) Harner, T.; Pozo, K.; Gouin, T.; Macdonald, A. M.; Hung, H.; Cainey, J.; Peters, A. Global pilot study for persistent organic pollutants (POPs) using PUF disk passive air samplers. Environ. Pollut. 2006, 144 (2), 445-452.

(31) Chakraborty, P.; Zhang, G.; Li, J.; Xu, Y.; Liu, X.; Tanabe, S.; Jones, K. C. Selected organochlorine pesticides in the atmosphere of major Indian Cities: Levels, regional versus local variations, and sources. Environ. Sci. Technol. 2010, 44 (21), 8038-8043.

(32) Cheng, H.; Deng, Z.; Chakraborty, P.; Liu, D.; Zhang, R.; Xu, Y.; Luo, C.; Zhang, G.; Li, J. A comparison study of atmospheric 
polycyclic aromatic hydrocarbons in three Indian cities using PUF disk passive air samplers. Atmos. Environ. 2013, 73, 16-21.

(33) Syed, J. H.; Malik, R. N.; Liu, D.; Xu, Y.; Wang, Y.; Li, J.; Zhang, G.; Jones, K. C. Organochlorine pesticides in air and soil and estimated air-soil exchange in Punjab, Pakistan. Sci. Tot. Environ. 2013, 444, $491-7$.

(34) Xu, Y.; Tian, C.; Zhang, G.; Ming, L.; Wang, Y.; Chen, Y.; Tang, J.; Li, J.; Luo, C. Influence of monsoon system on alpha-HCH fate in Asia: A model study from 1948 to 2008. J. Geophys. Res.-Atmos. 2013, 118 (12), 6764-6770.

(35) Source, C. C. Capitaline \& Company Source. http://www. capitaline.com/new/index.asp (accessed October 2, 2013).

(36) Bohlin, P.; Jones, K. C.; Strandberg, B. Occupational and indoor air exposure to persistent organic pollutants: A review of passive sampling techniques and needs. J. Environ. Monit. 2007, 9 (6), 501509.

(37) Chaemfa, C.; Barber, J. L.; Huber, S.; Breivik, K.; Jones, K. C. Screening for PFOS and PFOA in European air using passive samplers. J. Environ. Monit. 2010, 12 (5), 1100-1109.

(38) Shoeib, M.; Harner, T. Characterization and comparison of three passive air samplers for persistent organic pollutants. Environ. Sci. Technol. 2002, 36 (19), 4142-4151.

(39) Pozo, K.; Harner, T.; Lee, S. C.; Sinha, R. K.; Sengupta, B.; Loewen, M.; Geethalakshmi, V.; Kannan, K.; Volpi, V. Assessing seasonal and spatial trends of persistent organic pollutants (POPs) in Indian agricultural regions using PUF disk passive air samplers. Environ. Pollut. 2011, 159 (2), 646-653.

(40) Lohmann, R.; Morgan, E.; Bollinger, K., Passive sampling of atmospheric POPs using polyethylene samplers. Abstracts of Papers of the American Chemical Society 2010, 239.

(41) Barber, J. L.; Sweetman, A. J.; Thomas, G. O.; Braekevelt, E.; Stern, G. A.; Jones, K. C. Spatial and temporal variability in air concentrations of short-chain (C-10-C-13) and medium-chain (C-14$\mathrm{C}$-17) chlorinated n-alkanes measured in the UK atmosphere. Environ. Sci. Technol. 2005, 39 (12), 4407-4415.

(42) Syed, J. H.; Malik, R. N.; Liu, D.; Xu, Y.; Wang, Y.; Li, J.; Zhang, G.; Jones, K. C. Organochlorine pesticides in air and soil and estimated air-soil exchange in Punjab, Pakistan. Sci. Total Environ. 2013, 444 (0), 491-497.

(43) Reth, M.; Zencak, Z.; Oehme, M. New quantification procedure for the analysis of chlorinated paraffins using electron capture negative ionization mass spectrometry. J. Chromatogr., A 2005, 1081 (2), 225231.

(44) Reth, M.; Oehme, M. Limitations of low resolution mass spectrometry in the electron capture negative ionization mode for the analysis of short- and medium-chain chlorinated paraffins. Anal. Bioanal. Chem. 2004, 378 (7), 1741-1747.

(45) Harner, T.; Su, K.; Genualdi, S.; Karpowicz, J.; Ahrens, L.; Mihele, C.; Schuster, J.; Charland, J.-P.; Narayan, J. Calibration and application of PUF disk passive air samplers for tracking polycyclic aromatic compounds (PACs). Atmos. Environ. 2013, 75 (0), 123-128.

(46) Wang, X.-T.; Zhang, Y.; Miao, Y.; Ma, L.-L.; Li, Y.-C.; Chang, Y.-Y.; Wu, M.-H. Short-chain chlorinated paraffins (SCCPs) in surface soil from a background area in China: Occurrence, distribution, and congener profiles. Environ. Sci. Pollut. Res. 2013, 20 (7), 4742-4749.

(47) Gao, Y.; Zhang, H.; Su, F.; Tian, Y.; Chen, J. Environmental occurrence and distribution of short chain chlorinated paraffins in sediments and soils from the Liaohe River Basin, P. R. China. Environ. Sci. Technol. 2012, 46 (7), 3771-3778.

(48) Drouillard, K. G.; Tomy, G. T.; Muir, D. C. G.; Friesen, K. J. Volatility of chlorinated n-alkanes (C10-C12): Vapor pressures and Henry's law constants. Environ. Toxicol. Chem. 1998, 17 (7), 12521260.

(49) Friden, U. E.; McLachlan, M. S.; Berger, U. Chlorinated paraffins in indoor air and dust: Concentrations, congener patterns, and human exposure. Environ. Int. 2011, 37 (7), 1169-1174.

(50) Thanh, W.; Han, S.; Yuan, B.; Zeng, L.; Li, Y.; Wang, Y.; Jiang, G. Summer-winter concentrations and gas-particle partitioning of short chain chlorinated paraffins in the atmosphere of an urban setting. Environ. Pollut. 2012, 171, 38-45.

(51) Peters, A. J.; Tomy, G. T.; Jones, K. C.; Coleman, P.; Stern, G. A. Occurrence of C-10-C-13 polychlorinated n-alkanes in the atmosphere of the United Kingdom. Atmos. Environ. 2000, 34 (19), $3085-3090$. 